\title{
Incomplete Double Aortic Arch and Window Patent Ductus Arteriosus in a CHARGE Syndrome Patient: A Case Report and Review of Literature
}

\author{
Gregory P Moore ${ }^{\mathrm{a}, \mathrm{e}}$, Hannah Roberts ${ }^{\mathrm{b}}$, Gyaandeo Maharajh ${ }^{\mathrm{c}}$, Lillian SW Lai ${ }^{\mathrm{d}}$
}

\begin{abstract}
We report on a female infant with CHARGE syndrome who has a previously undescribed combination of two very rare cardiac anomalies: incomplete double aortic arch and "window" patent ductus arteriosus (PDA). The term infant went into heart failure at four weeks of age due to the extremely large PDA. Due to its unusual anatomy and the risk of damage to nearby vital vessels with ligation, the PDA was divided and closed using a patch on both ends while the patient was on cardiopulmonary bypass. Only in retrospect was the rare diagnosis of this "window" PDA and abnormal arch made. This case is the first to demonstrate a "window" PDA and an incomplete double aortic arch consisting of a dominant right aortic arch and persistent proximal left dorsal aorta and the first to provide three-dimensional MRI angiography images of the anatomy. The case provides several key learning points. As cardiac MRI is now a standard imaging tool it is important that physicians be made aware of how the above rare diagnoses appear on threedimensional angiography. Thorough attention to the cardiac anatomy of patient with CHARGE must continue. We report this case to help physicians successfully diagnose and manage this type of rare anatomy and provide long-term follow-up results that have not been published previously.
\end{abstract}

Keywords: Anomaly; Aortic Arch; CHARGE syndrome; Ductus Arteriosus, Patent; Aorta, Thoracic; Aortic Arch; Arch of the Aorta;

\footnotetext{
Manuscript accepted for publication January 2, 2013

aDepartment of Pediatrics, Division of Neonatology, Children's Hospital of Eastern Ontario and, Department of Obstetrics and Gynecology, Division of Newborn Care, The Ottawa

Hospital - General Campus; Canada

${ }^{\mathrm{b}}$ Faculty of Medicine, University of Ottawa; Canada

'Department of Surgery, Division of Cardiovascular Surgery, Children's Hospital of Eastern Ontario; Canada

${ }^{\mathrm{d}}$ Department of Pediatrics, Division of Cardiology, Children's Hospital of Eastern Ontario, Canada

${ }^{\mathrm{e}}$ Corresponding author: Gregory P Moore, The Ottawa

Hospital - General Campus, Division of Newborn Services - Box 806, 501 Smyth Road, Ottawa, ON, K1H 8L6, Canada.

Email: gmoore@cheo.on.ca
}

doi: http://dx.doi.org/10.4021/jmc1047w
Window patent ductus arteriosus

\section{Introduction}

The first patients with CHARGE association were described in 1961 [1]. Much progress has been made since: most patients [1] meeting the criteria for CHARGE have a mutation in the CHD7 gene on chromosome 8 though the genotypephenotype predictions remain imprecise [1-4]. Congenital heart defects (CHD) are a common presenting feature of CHARGE [5] and occur in $75-85 \%$ of cases [1-3]. Patent ductus arteriosus (PDA) is historically the most common CHD [5-8]. Others include aortic arch (AA) anomalies, tetralogy of Fallot, and ventricular or atrial septal defects [2, $5,9,10]$.

We present a neonate with CHARGE syndrome who has a "window" PDA and a never described type of incomplete double AA (DAA): a dominant RAA with persistence of the proximal left dorsal aorta. To our knowledge, our patient's combined cardiac findings have never been reported, let alone with CHARGE syndrome. There have been only 6 case reports of a window PDA [11-16]: three were based on post-mortem autopsies, only one describes an association with a RAA and none report an association with CHARGE syndrome. We also present for the first time a "window" PDA imaged by three-dimensional (3D) MRI angiography. We describe the embryological underpinnings of the anomalies and outline key learning points.

\section{Case Report}

A female infant was born at 38 weeks gestation to a healthy, 30 year old mother. Prenatal screening suggested Trisomy 21; however, amniocentesis revealed a normal 46XX karyotype. Pre-natal ultrasounds showed a two vessel cord, an absent stomach and polyhydramnios. A tracheo-esophageal fistula (TEF) was suspected. Three days prior to delivery, an ultrasound demonstrated persistent polyhydramnios and a plateau in fetal growth. Cesarean section occurred for a non-reassuring fetal heart rate. Apgar scores were 9 and 9. A 


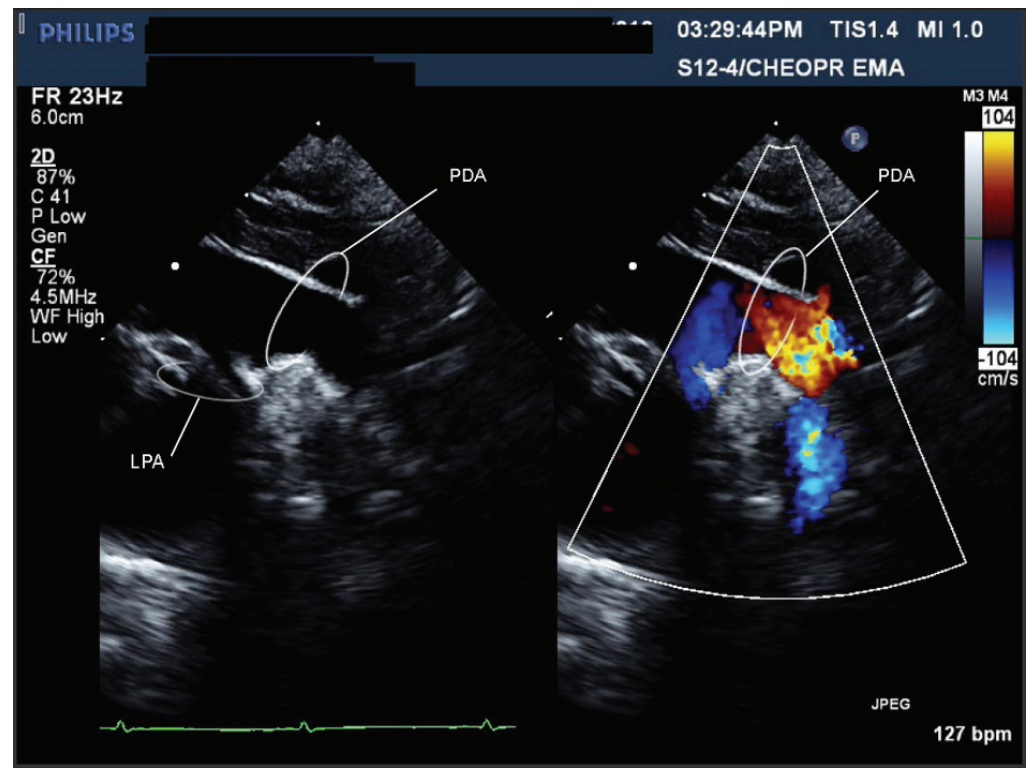

Figure 1, Movie 1. A large PDA (with left to right shunt) was seen measuring $0.72 \mathrm{~cm}$ in diameter, compared to a descending aorta diameter of $0.69 \mathrm{~cm}$. Suspected to be on the right side as there was a RAA.

chest X-ray revealed a nasogastric tube coiled in the esophagus thus confirming a TEF.

The infant was transferred to the neonatal intensive care unit and remained stable on room air. A systolic murmur and low set ears were noted. An ultrasound showed bilateral renal hypoplasia. Bilateral optic nerve colobomas and hearing loss were diagnosed. On echocardiography (ECHO), the AA anatomy was difficult to delineate. On the typical sweep for branching pattern, the appearance was consistent with a very large PDA (Fig. 1) (Movie 1, supplementary data) and a DAA [17] with a dominant right AA (RAA) (Fig. 2) (Movie 2 , supplementary data). Intracardiac anatomy, size, and function were normal. Consequently, CHARGE syndrome was suspected and confirmed (CHD7 gene mutation).

A cardiac MRI was performed on day of life five to better define the AA anatomy. The MRI showed a RAA with only two branches. The first was a suspected large brachiocephalic trunk $(\mathrm{BCT})$ giving rise to the right common carotid

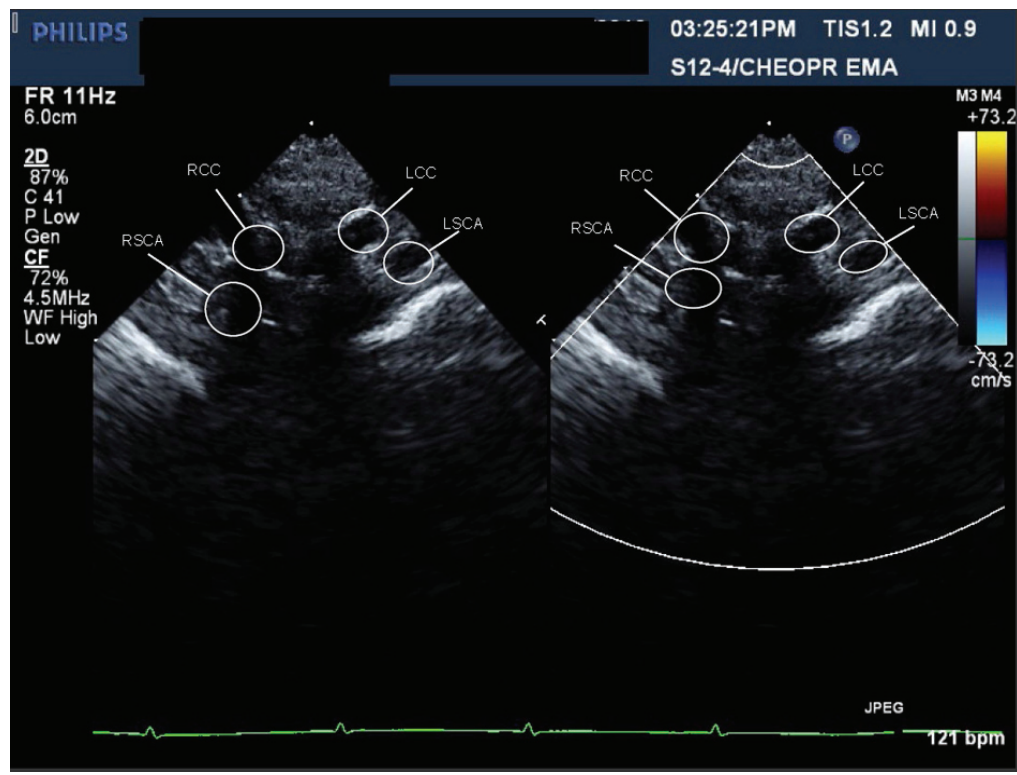

Figure 2, Movie 2. Echocardiographic sweep showing a suspected double aortic arch. 


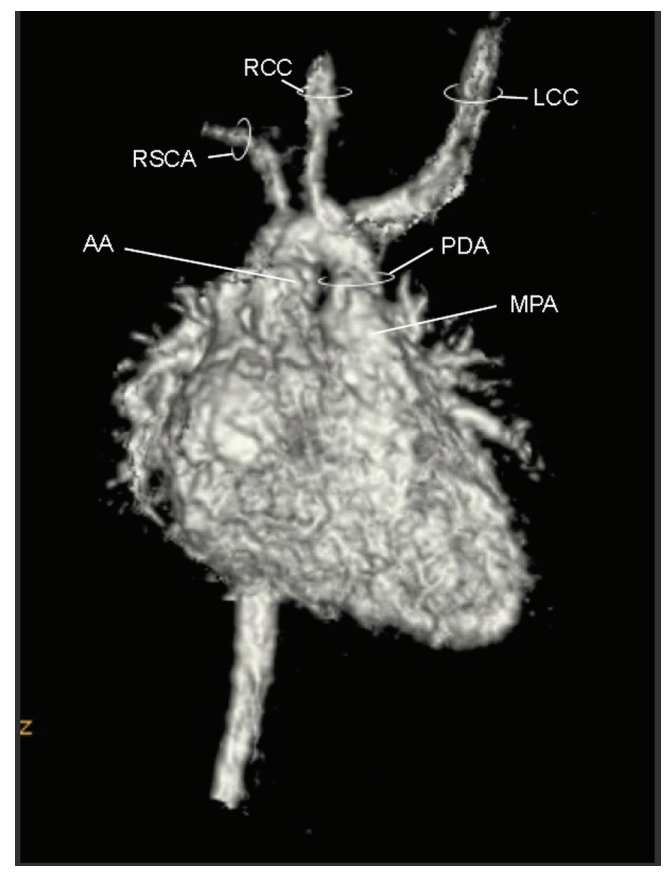

Figure 3, Movie 3. 3D MRI angiogram reconstruction. The study was performed without general anesthetic knowing that some respiratory artifact would be acceptable. The first branch was a suspected BCT giving rise to the RCCA, LCCA, and LSCA, the second branch was the RSCA.

artery (RCCA), left common carotid artery (LCCA), and left subclavian artery (LSCA) (Fig. 3) (Movie 3, supplementary data). The second branch was the right subclavian artery (RSCA). The PDA was large and unusually oriented; it appeared to connect the main pulmonary artery (MPA) (close to the left pulmonary artery (LPA) origin) to the AA right at the base of the suspected BCT. The MRI suggested there was neither a vascular ring nor a DAA.

Although the precise classification of this AA remained uncertain, the hemodynamic were clear. The patient developed heart failure at four weeks of age due to the persistently large PDA. Ligation by median sternotomy (due to the odd orientation of the PDA) occurred at 5 weeks.

Intraoperatively, the MRI anatomy was verified. However, the surgeon felt the length of the PDA too short for simple ligation, as ligation might compromise the takeoff of the LSCA and/or the LPA (Fig. 4a). The patient was placed on cardiopulmonary bypass, the PDA transected and the two ends closed with patches of bovine pericardium (Fig. 4b). The PDA tissue had the texture of normal great vessel wall - indistinguishable from the MPA and aorta. The patient recovered uneventfully.

A repeat MRI was performed post-operatively (Fig. 5) (Movie 4, supplementary data). The uniqueness of the RAA became much clearer. The suspected BCT was oriented anteriorly such that blood from the ascending aorta took a U-turn to perfuse it. Off this trunk, the RCCA, LCCA and LSCA arose individually while the distal end was patched.

The patient was discharged at four months of age. The cardiologist saw her at 7 and 18 months of age. The cardiac exam was normal including four limb blood pressures. An ECHO showed no coarctation and unobstructed blood flow to the RAA and its branches (Fig. 6) (Movie 5, supplementary data). No further Cardiology follow-up was deemed necessary.

\section{Discussion}

To our knowledge, our patient's combined cardiac findings have never been reported, let alone with CHARGE syn-

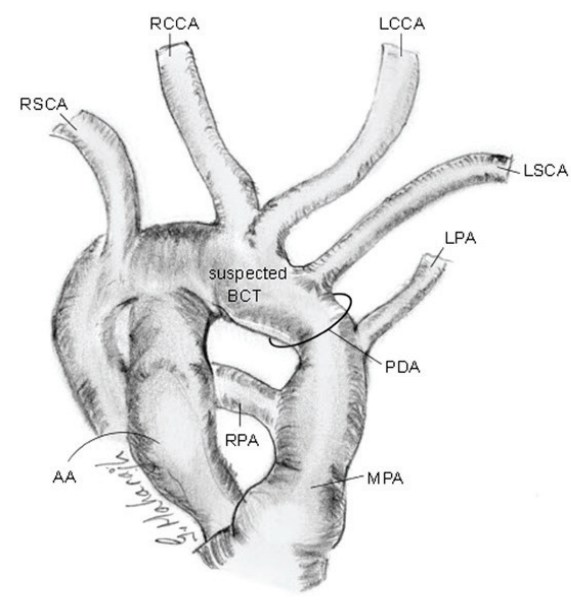

a

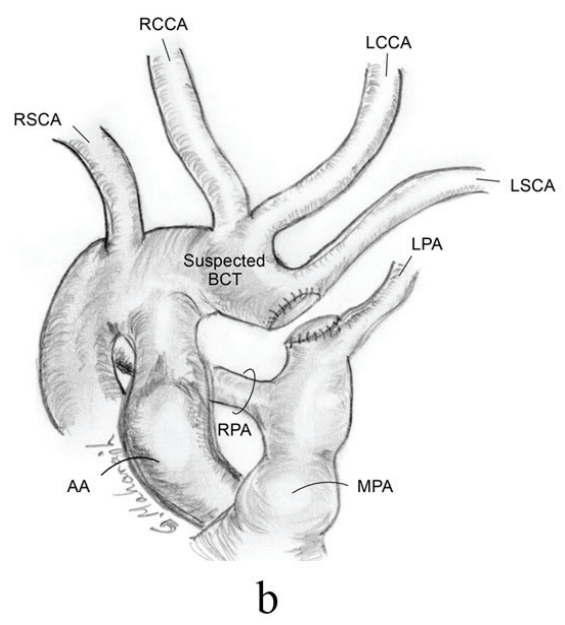

Figure 4. Schematic of intra-operative anatomy showing shortness in length of PDA and relationship of proximity of LPA and LSCA, pre-transection (a), and post-transection (b). 


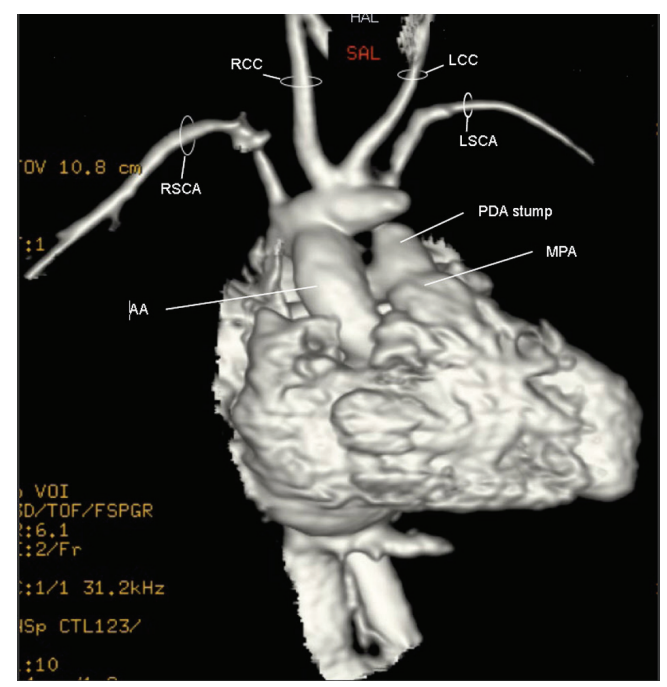

Figure 5, Movie 4. 3D MRI post-op: The suspected BCT was oriented anteriorly such that blood from the ascending aorta took a U-turn to perfuse it. Off the suspected BCT, the RCCA, LCCA and LSCA arose individually and the trunk's distal end was patched.

drome. This patient has: 1) a "window" PDA and; 2) a never described type of incomplete DAA: a dominant RAA with persistence of the proximal left dorsal aorta.

From the initial series of six pairs of embryonic aortic arches, the usual LAA develops through the systematic involution and persistence of specific arches [18]. The left 4th arch becomes the actual AA, while the 5th arches involute. The PDA is formed by the distal portion of the left 6 th arch while the right one involutes [19]. The right dorsal aorta distal to the RSCA involutes to allow for a left-sided AA (Fig. 7) [18]. The most common branching pattern consists of three branches: the BCT, LCCA, and LSCA [20]. The BCT branches into the RSCA and RCCA; the PDA connects the LPA near its origin to the proximal descending aorta. Variants from this AA pattern have been described in CHARGE with an aberrant R/LSCA seemingly the most common [5, 7, 8, 21-23]. A DAA associated with CHARGE appears much rarer with only one report found [24].

The uniqueness of our case lies in the AA branching pattern. From the 3D MRI (Fig. 5) (Movie 4, supplementary data), there appeared to be two main branches off a RAA. The first was the suspected BCT giving rise to the RCCA, LCCA and LSCA. The second branch was the RSCA. The suspected BCT is actually a large segment of a persistent left dorsal aorta (Fig. 8). Due to the failure of the LSCA to ascend cephalically and posteriorly, this segment embryologically had to persist in order to supply the LSCA, the left vertebral artery and the "window" PDA. A sharp U-shaped bend results between the ascending aorta and the left dorsal aorta as seen on MRI (Fig. 5) (Movie 4, supplementary data). This is a form of incomplete DAA which explains why the ECHO (Fig. 2) (Movie 2, supplementary data) imaging was consistent with a DAA [17]. Typically the terminology of an incomplete DAA refers to an atresia of one of the AA resulting in a vascular ring created by the persistent ligamentum of the atretic segment; this entity is rare but described [2528]. In our patient, there is no vascular ring as the left dorsal aorta distal to the LSCA completely involuted as confirmed in surgery. To our knowledge this is the first description of

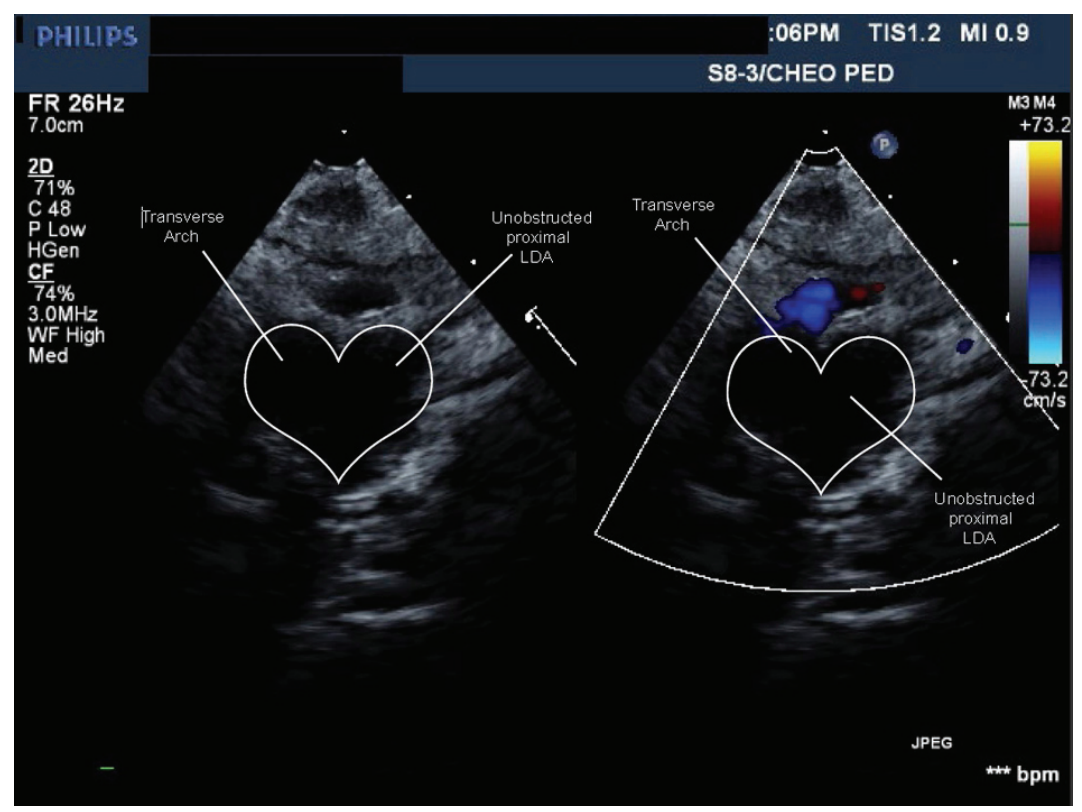

Figure 6, Movie 5. Echo study: forward flow from ascending aorta into large caliber persistent proximal left dorsal aorta then into head and neck vessels without obstruction or flow acceleration. 

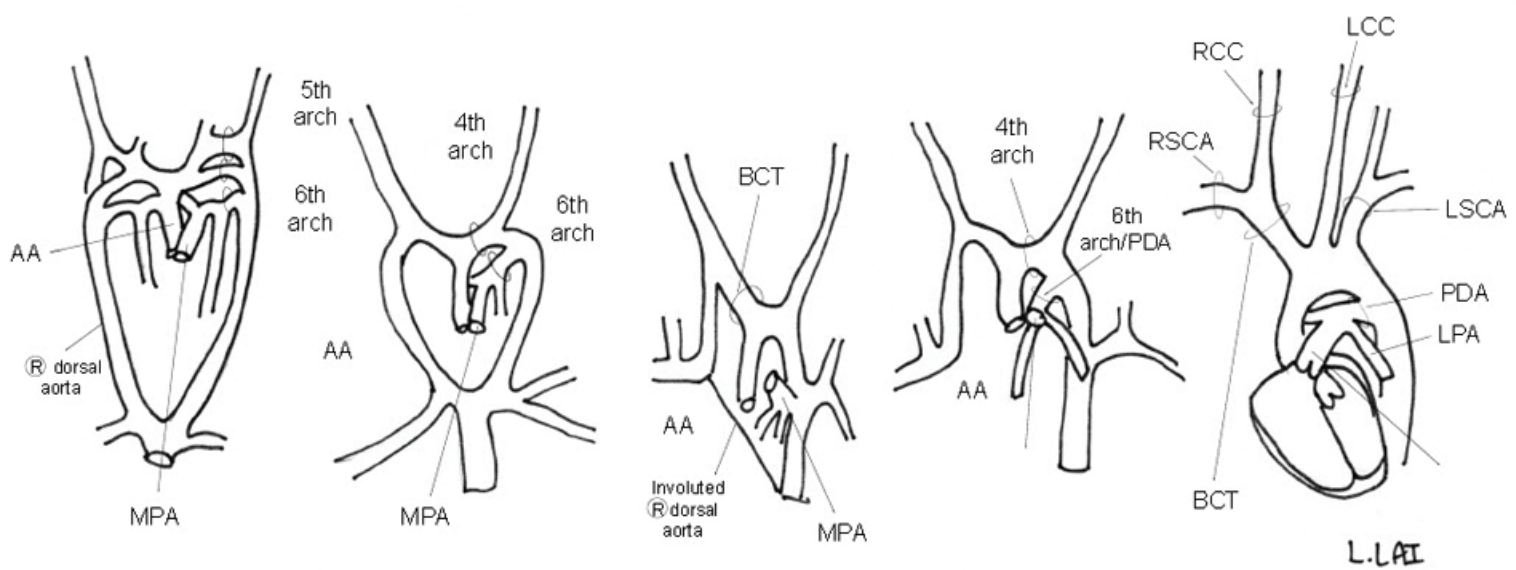

Figure 7. Schematic of embryologic development of a normal LAA

an incomplete DAA with involution of the distal left dorsal aorta but persistence of the proximal portion.

Our case is also unique as the PDA has a clear insertion into the MPA segment in an anterior-posterior fashion instead of the usual branch PA insertion. This anatomy supports Congdon's theory $[18,29]$ that the ventral half of the left 6th arch initially contributes to the formation of the MPA and later to the branch PA. More interestingly, the large but extremely short PDA and atypical PDA tissue, point us to the diagnosis of a "window" PDA - an extreme rarity. Five cases describe a "window" PDA associated with a LAA [11-14, 16]. Three were recognized at postmortem. Only one previous case describes an association with a RAA [15]. No reports were associated with CHARGE syndrome.

The diagnosis of a window PDA is commonly retrospective, where the initial PDA imaging is difficult to discern. The final clinical descriptions are all similar intra-operatively: the PDA appears short, almost non-apparent on external inspection, with the MPA appearing continuous with the aorta, and the PDA tissue is similar to aortic tissue. Histologi-

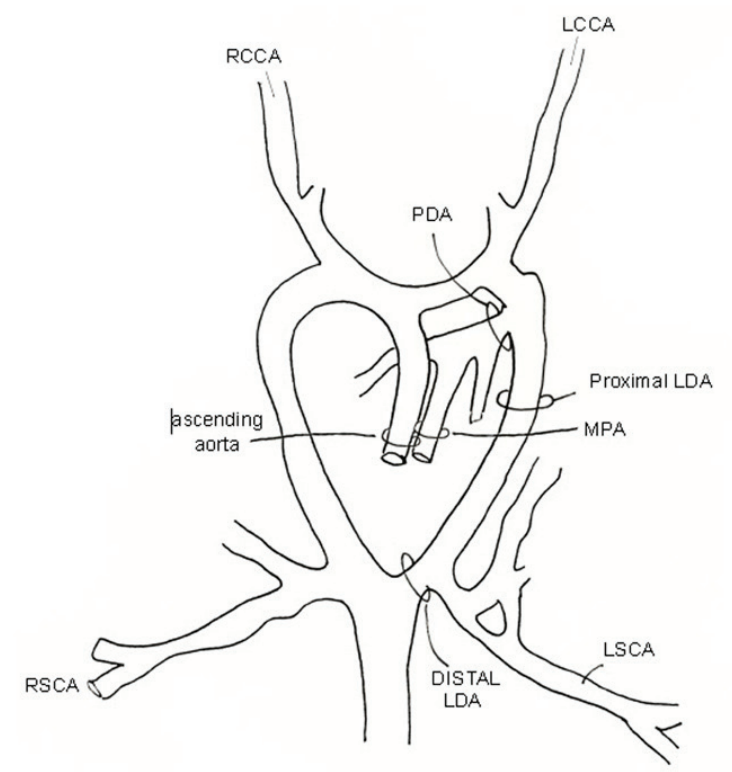

a

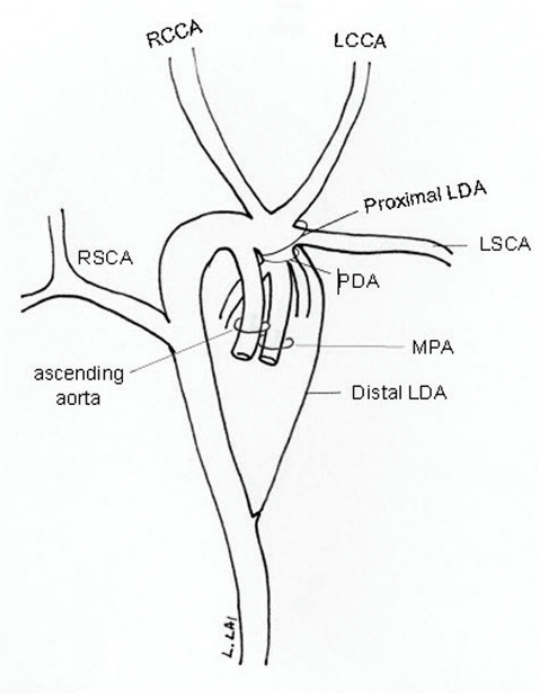

$\mathrm{b}$

Figure 8. The suspected BCT is actually a large segment of a persistent proximal left dorsal aorta (LDA) (a) making this an incomplete double aortic arch with involution of the distal portion of the left dorsal aorta (b). 
cally, the tissue contains little or no circular medial musculature and few or no intimal pads that are required to "close" the PDA [12]. Pathology specimens from our case may have assisted in the diagnosis but, given the shortness of the PDA, were not attainable. A patch closure may be the safest way to close such a "window" PDA [11-13], although Vida et al [15] closed one by dividing and suturing it.

\section{Conclusion}

In summary, this case demonstrates an incomplete DAA with a large persistent segment of the left dorsal aorta coupled with a "window" PDA. Several important learning points arise. Firstly, as MRI is now a standard technique when $\mathrm{ECHO}$ assessment is unclear, practitioners must become familiar with these rare cases so that a proper, timely diagnosis is made. We present for the first time a "window" PDA imaged by 3D MRI angiography. The impact on clinical management is notable, as a "window" PDA is unlikely to close spontaneously. Therefore, with early diagnosis, intervention could occur prior to a patient developing congestive heart failure. Furthermore, surgical mishaps have occurred without understanding the possibility of a "window" PDA. One paper reports a mistaken ligation of the descending aorta as it appeared smaller than the PDA [12]. Based on our management success and previous case reports, patch closure with cardiopulmonary support may be the best option.

Secondly, the risk of interrupting blood flow to head and neck vessels must be recognized in this AA anatomy. Given the orientation of the persistent left dorsal aorta, the blood exiting the ascending aorta must flow around a "U-turn" before entering these vessels. No other published papers describe this entity with such clear imaging and long-term follow-up.

Finally, this case reinforces the need for detailed attention to the cardiac anatomy in patients with CHARGE syndrome $[7,21]$. Aside from case reports, recent published literature rarely describes PDA management in CHARGE [21, 24, 30, 31]. Management was last detailed 20 years ago [7]. This area warrants further research.

\section{Acknowledgement}

Thank you to the patient's parents for agreeing to dissemination of their daughter's information. Thank you to Dr. Richard Van Praagh for his insight on this patient's cardiac anatomy. The authors have no conflicts of interest to declare.

\section{Competing Interests}

The authors declare that they have no competing interests. No external funding was secured for this study. The authors have no financial relationships relevant to this article to disclose.

\section{Authors' Contributions}

GMoore conceptualized the idea and organized the compilation of data by overseeing the medical student (Hannah Roberts) involved. He performed a thorough literature search and wrote, edited, revised and approved the final manuscript as submitted.

HR carried out the initial fact finding and information gathering of the case material, performed a thorough literature search, drafted parts of the initial manuscript and abstract and approved the final manuscript as submitted.

GM critically reviewed the manuscript, provided the surgical intra-operative information and drew some of the schematic diagrams and approved the final manuscript as submitted.

LL performed a thorough literature search, critically reviewed and edited the manuscript, acquired and made the patient related images and movies, drew some of the schematic diagrams, diagnosed the rare cardiac anatomy by seeking out experts in the field, and approved the final manuscript as submitted.

\section{Abbreviations}

AA: aortic arch; BCT: brachiocephalic trunk; CHD: congenital heart defects; DAA: double aortic arch; ECHO: echocardiogram; LCCA: left common carotid artery; LPA: left pulmonary artery; LSCA: left subclavian artery; MPA: main pulmonary artery; PDA: patent ductus arteriosus; PFO: patent foramen ovale; RAA: right aortic arch; RCCA: right common carotid artery; RSCA: right subclavian artery; TEF: tracheo-esophageal fistula; 3D: three-dimensional

\section{References}

1. Bergman JE, Janssen N, Hoefsloot LH, Jongmans MC, Hofstra RM, van Ravenswaaij-Arts CM. CHD7 mutations and CHARGE syndrome: the clinical implications of an expanding phenotype. J Med Genet. 2011;48(5):334-342.

2. Blake KD, Prasad C. CHARGE syndrome. Orphanet J Rare Dis. 2006;1:34.

3. Lalani SR, Safiullah AM, Fernbach SD, Harutyunyan KG, Thaller C, Peterson LE, McPherson JD, et al. Spectrum of CHD7 mutations in 110 individuals with CHARGE syndrome and genotype-phenotype correlation. Am J Hum Genet. 2006;78(2):303-314.

4. Jongmans MC, Admiraal RJ, van der Donk KP, Vissers 
LE, Baas AF, Kapusta L, van Hagen JM, et al. CHARGE syndrome: the phenotypic spectrum of mutations in the CHD7 gene. J Med Genet. 2006;43(4):306-314.

5. Lin AE, Chin AJ, Devine W, Park SC, Zackai E. The pattern of cardiovascular malformation in the CHARGE association. Am J Dis Child. 1987;141(9):1010-1013.

6. Cyran SE, Martinez R, Daniels S, Dignan PS, Kaplan S. Spectrum of congenital heart disease in CHARGE association. J Pediatr. 1987;110(4):576-578.

7. Wyse RK, al-Mahdawi S, Burn J, Blake K. Congenital heart disease in CHARGE association. Pediatr Cardiol. 1993;14(2):75-81.

8. Tellier AL, Cormier-Daire V, Abadie V, Amiel J, Sigaudy S, Bonnet D, de Lonlay-Debeney P, et al. CHARGE syndrome: report of 47 cases and review. Am J Med Genet. 1998;76(5):402-409.

9. Issekutz KA, Graham JM, Jr., Prasad C, Smith IM, Blake KD. An epidemiological analysis of CHARGE syndrome: preliminary results from a Canadian study. Am J Med Genet A. 2005;133A(3):309-317.

10. Zentner GE, Layman WS, Martin DM, Scacheri PC. Molecular and phenotypic aspects of CHD7 mutation in CHARGE syndrome. Am J Med Genet A. 2010;152A(3):674-686.

11. Agarwal V, Mustaev M. The window ductus: Circulatory arrest as an option for surgical repair. Ann Pediatr Cardiol. 2010;3(2):163-165.

12. Grunenfelder J, Bartram U, Van Praagh R, Bove KE, Bailey WW, Meyer RA, Koenig PR, et al. The large window ductus: a surgical trap. Ann Thorac Surg. 1998;65(6):1790-1791.

13. Komeda M, Miki S, Kusuhara K, Ueda Y, Okita Y, Tahata T, Tamura T, et al. [Report of a case of an atypical huge patent ductus arteriosus]. Kyobu Geka. 1989;42(1):3539.

14. Lev M: Autopsy diagnosis of congenitally malformed hearts. Springfield, Ill: Charles C Thomas; 1953.

15. Vida VL, Veras O, Leon-Wyss J, Vides I, Castaneda AR. The right-sided window ductus: a rare anatomical entity. Ann Thorac Surg. 2006;81(3):1126-1127.

16. Wee AS, Tock EP. Window type of ductus arteriosus with shunt reversal. Singapore Med J. 1967;8(4):271274.

17. Murdison KA. Ultrasonic Imaging of Vascular Rings and Other Anomalies Causing Tracheobronchial Compression. Echocardiography. 1996;13(3):337-356.

18. Congdon ED: Transformation of the aortic-arch system during the development of the human embryo. Contrib
Embryol Carneg Instn 1922, 14: 47-110.

19. Forsey JT, Elmasry OA, Martin RP. Patent arterial duct. Orphanet J Rare Dis. 2009;4:17.

20. Muller M, Schmitz BL, Pauls S, Schick M, Rohrer S, Kapapa T, Schlotzer W. Variations of the aortic arch - a study on the most common branching patterns. Acta Radiol. 2011;52(7):738-742.

21. Bech AP, op den Akker J, Matthijsse PR. Isolation of the left subclavian artery from the pulmonary artery in a patient with CHARGE association. Congenit Anom (Kyoto). 2010;50(3):200-202.

22. Ghalili K, Issenberg HJ, Freeman NJ, Brodman RF. Isolated left carotid artery in CHARGE association: diagnosis and repair. Ann Thorac Surg. 1990;50(1):130-132.

23. Martin D, Knez I, Rigler B. Anomalous origin of the brachiocephalic trunk from the left pulmonary artery with CHARGE syndrome. Thorac Cardiovasc Surg. 2006;54(8):549-551.

24. Hsueh KF, Yang CS, Lu JH, Hsu WM. Clinical characteristics of CHARGE syndrome. J Chin Med Assoc. 2004;67(10):542-546.

25. Schlesinger AE, Krishnamurthy R, Sena LM, Guillerman RP, Chung T, DiBardino DJ, Fraser CD, Jr. Incomplete double aortic arch with atresia of the distal left arch: distinctive imaging appearance. AJR Am J Roentgenol. 2005;184(5):1634-1639.

26. Oguz B, Haliloglu M, Karcaaltincaba M. Paediatric multidetector CT angiography: spectrum of congenital thoracic vascular anomalies. Br J Radiol. 2007;80(953):376383.

27. Trapali C, Nika A, Papaphylactou M, Iacovidou N. A rare type of double aortic arch diagnosed by echocardiography in an asymptomatic 9-year-old patient. Pediatr Cardiol. 2010;31(5):728-731.

28. Dillman JR, Attili AK, Agarwal PP, Dorfman AL, Hernandez RJ, Strouse PJ. Common and uncommon vascular rings and slings: a multi-modality review. Pediatr Radiol. 2011;41(11):1440-1454; quiz 1489-1490.

29. Kasai T, Kurotaki M, Aiyama S. Anomalous insertion of the persisting right or left ductus arteriosus. Okajimas Folia Anat Jpn. 1968;44(2):159-171.

30. Pardo JM, Chua C. The CHARGE association in a male newborn infant. Diagnostic and therapeutic considerations. Clin Pediatr (Phila). 1985;24(9):531-533.

31. Searle LC, Graham JM, Jr., Prasad C, Blake KD. CHARGE syndrome from birth to adulthood: an individual reported on from 0 to 33 years. Am J Med Genet A. $2005 ; 133 \mathrm{~A}(3): 344-349$. 